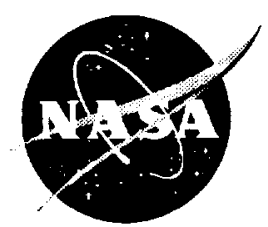

\title{
Experimental and Numerical Investigation of Losses in Low-Pressure Turbine Blade Rows
}

Daniel J. Dorney

Virginia Commonwealth University, Richmond, Virginia

James P. Lake

AFRL/PRRS

Edwards Air Force Base, California

Paul I. King

Air Force Institute of Technology

Wright-Patterson Air Force Base, Ohio

David E. Ashpis

Glenn Research Center, Cleveland, Ohio 
The NASA STI Program Office . . in Profile

Since its founding, NASA has been dedicated to the advancement of aeronautics and space science. The NASA Scientific and Technical Information (STI) Program Office plays a key part in helping NASA maintain this important role.

The NASA STI Program Office is operated by Langley Research Center, the Lead Center for NASA's scientific and technical information. The NASA STI Program Office provides access to the NASA STI Database, the largest collection of aeronautical and space science STI in the world. The Program Office is also NASA's institutional mechanism for disseminating the results of its research and development activities. These results are published by NASA in the NASA STI Report Series, which includes the following report types:

- TECHNICAL PUBLICATION. Reports of completed research or a major significant phase of research that present the results of NASA programs and include extensive data or theoretical analysis. Includes compilations of significant scientific and technical data and information deemed to be of continuing reference value. NASA's counterpart of peerreviewed formal professional papers but has less stringent limitations on manuscript length and extent of graphic presentations.

- TECHNICAL MEMORANDUM. Scientific and technical findings that are preliminary or of specialized interest, e.g., quick release reports, working papers, and bibliographies that contain minimal annotation. Does not contain extensive analysis.

- CONTRACTOR REPORT. Scientific and technical findings by NASA-sponsored contractors and grantees.
- CONFERENCE PUBLICATION. Collected papers from scientific and technical conferences, symposia, seminars, or other meetings sponsored or cosponsored by NASA.

- SPECIAL PUBLICATION. Scientific, technical, or historical information from NASA programs, projects, and missions, often concerned with subjects having substantial public interest.

- TECHNICAL TRANSLATION. Englishlanguage translations of foreign scientific and technical material pertinent to NASA's mission.

Specialized services that complement the STI Program Office's diverse offerings include creating custom thesauri, building customized data bases, organizing and publishing research results ... even providing videos.

For more information about the NASA STI Program Office, see the following:

- Access the NASA STI Program Home Page at http://www.sti.nasa.gov

- E-mail your question via the Internet to help@sti.nasa.gov

- Fax your question to the NASA Access Help Desk at (301) 621-0134

- Telephone the NASA Access Help Desk at (301) 621-0390

- Write to:

NASA Access Help Desk

NASA Center for AeroSpace Information 7121 Standard Drive Hanover, MD 21076 


\section{Experimental and Numerical Investigation of Losses in Low-Pressure Turbine Blade Rows}

Daniel J. Dorney

Virginia Commonwealth University, Richmond, Virginia

James P. Lake

AFRL/PRRS

Edwards Air Force Base, California

Paul I. King

Air Force Institute of Technology

Wright-Patterson Air Force Base, Ohio

David E. Ashpis

Glenn Research Center, Cleveland, Ohio

Prepared for the 38th Aerospace Sciences Meeting and Exhibit

sponsored by the American Institute of Aeronautics and Astronautics

Reno, Nevada, January 10-13, 2000

National Aeronautics and

Space Administration

Glenn Research Center 


\section{Acknowledgments}

The work of the first author was supported by NASA Glenn Research Center under Grant NCC3-645.

Trade names or manufacturers' names are used in this report for identification only. This usage does not constitute an official endorsement, either expressed or implied, by the National Aeronautics and Space Administration.

Available from

NASA Center for Aerospace Information

7121 Standard Drive

Hanover, MD 21076

Price Code: $\mathrm{A} 03$
National Technical Information Service 5285 Port Royal Road Springfield, VA 22100 Price Code: A03 


\section{EXPERIMENTAL AND NUMERICAL INVESTIGATION OF LOSSES IN LOW-PRESSURE TURBINE BLADE ROWS}

\author{
Daniel J. Dorney * \\ Virginia Commonrealth Iniversity \\ Richmond. It \\ Paul I. King ${ }^{b}$ \\ Air Force Institute of Technology \\ Wright-Patterson AFB, OH
}

\author{
James P. Lake ${ }^{2}$ \\ AFRL/PRRS \\ Edwards AFB, CA \\ David E. Ashpis ${ }^{c}$ \\ NASA Glenn Research Center \\ Cleveland, $\mathrm{OH}$
}

\begin{abstract}
Experimental data and numerical simulations of low-pressure turbines have shown that unsteady blade row interactions and separation can have a significant impact on the turbine efficiency. Measured turbine efficiencies at takeoff can be as much as two points higher than those at cruise conditions. Several recent studies have revealed that the performance of low-pressure turbine blades is a strong function of the Reynolds number. In the current investigation, experiments and simulations have been performed to study the behavior of a low-pressure turbine blade at several Reynolds numbers. Both the predicted and experimental results indicate increased cascade losses as the Reynolds number is reduced to the values associated with aircraft cruise conditions. In addition, both sets of data show that tripping the boundary layer helps reduce the losses at lower Reynolds numbers. Overall, the predicted aerodynamic and performance results exhibit fair agreement with experimental data.
\end{abstract}

\section{NOMENCLATURE}

$b_{x} \quad$ Axial chord

$C_{f} \quad$ Skin friction coefficient

$C_{P} \quad\left(P_{t 1}-P\right) /\left(1 / 2 \rho U^{2}{ }_{1}\right)$

$M \quad$ Mach number

$P \quad$ Pressure

P.S. Pressure surface

$P_{t} \quad$ Total Pressure

\footnotetext{
*Associate Professor, Senior Member AIAA.

a Research Engineer, Member AIAA.

b Associate Professor, Senior Member AIAA.

c Aerospace Engineer, Senior Member AIAA.
}

Re Reynolds number (axial chord, inlet vel.)

$S \quad$ Entropy, arc-length distance

S.S. Suction surface

$U \quad$ Free stream velocity

$X$ Axial-direction

$\alpha \quad$ Absolute reference frame flow angle

$\delta^{*} \quad$ Displacement thickness

$T u$ Turbulence intensity

$\omega \quad$ Loss, $\left(P_{t 1}-P_{t 2}\right) /\left(1 / 2 \rho U_{1}^{2}\right)$

\section{SUBSCRIPTS}

expt Experiment

pred Predicted

1 Blade inlet

$2 \quad$ Blade exit

\section{INTRODUCTION}

Experimental data from jet-engine tests have indicated that unsteady blade row (wake) interactions and separation can have a significant impact on the efficiency of turbine stages. The effects of these interactions can be intensified in low-pressure turbine stages because of the low Reynolds number operating environment. Measured turbine efficiencies at takeoff can be as much as two points higher than those at cruise conditions [1]. Thus, during the last decade a significant amount of effort has been put into determining the effects of transition and turbulence on the performance of low pressure turbine stages. Experimental investigations have been performed, for example, by Hodson et al. [2, 3], Halstead $\epsilon t$ al. [4, 5], Qiu et al. [6], Sohn et al. [7] and Boyle et al. [8]. These investigations have helped identify/clarify the roles that factors such as the Reynolds number, free stream 
turbulence intensity, pressure gradient and curvature have in the generation of losses. In particular, it has been determined that [1]:

- At low to moderate Reynolds numbers there is a laminar region extending some distance from the leading edge.

- The boundary layer may separate, particularly on the suction surface of the blade. Separation may occur in the form of a closed bubble, or as massive separation with no reattachment (resulting in large losses). The pressure surface may have cove separation, and small separation bubbles may exist near the leading edge. The separation bubbles often originate in transitional flow, while reattachment is usually in turbulent flow.

- The interaction of incoming wakes with the boundary layer often creates a convected transitional or turbulent patch, which is trailed by a "calmed" region. The calmed region is a relaxation region between the patch and the laminar boundary layer.

More recently, Lake et al. [9, 10] performed experiments for the PAK-B blade, which was developed by Pratt \& Whitney to operate at low speeds while at taining loadings similar to those achieved at engine conditions. The study of Lake presented boundary profiles and loss data for three Reynolds numbers. In addition, the use of dimples and grooves for reducing losses at low Reynolds numbers was investigated.

In parallel to the experimental investigations, there have been significant analytical efforts to improve the modeling of transition. Examples of such efforts include the works of Mayle [11], Reshotko [12] and Gostelow et al. $[13,14]$. These newer models show promise of providing accurate transition predictions over a wide rangle of flow conditions [15], although they have yet to be implemented into the numerical flow analyses used by the turbine design community. Some recent computational investigations of interest include the works of Chernobrovkin and Lakshminarayana [16], Kang and Lakshminarayana [17], Huang and Xiong [18] and Dorney and Ashpis [19]. The work of Dorney and Ashpis, similar to the experimental efforts of Lake et al., involved the PAK-B geometry (although at higher Mach numbers).

The focus of the current effort has been to study the performance of low-pressure turbine airfoils by coordinating experiments and simulations for the PAK$B$ geometry. The PAK-B airfoil design was chosen because it generates a loading profile similar to the rotors found in modern aircraft engines. The comparison of the experimental and numerical results in- cludes boundary layer profiles, airfoil loadings and losses.

\section{EXPERIMENTAL CONFIGURATION}

The experimental data was obtained using the Air Force Research Laboratory low-speed linear cascade tunnel (see Fig. 1) at Wright-Patterson Air Force Base. The wind tunnel is a modified Aerolab drawdown tumel using a variable frequency motor driving an axial flow fan with a diameter of $128.6 \mathrm{~cm}(50.6$ inches). The tunnel modifications include a new adjustable turbine cascade test section inserted between the original tunnel inlet and exit, and a turbulencegenerating grid. The fan is driven by a 93.2-kilowatt (125 HP) motor pulling room air through the 304.8 $\mathrm{cm}$ (120 inch) wide by $266.7 \mathrm{~cm}$ (105 inch) high bell mouth inlet. The inlet contains honeycomb flow straighteners and converges to a test section size of $121.9 \mathrm{~cm}$ ( 48 inches) wide by $87.6 \mathrm{~cm}$. (34.5 inches) high. The tunnel is capable of test section speeds from 3 to $20 \mathrm{~m} / \mathrm{s}$ operating in room air with a turbulence intensity of approximately $1 \%$.

To simulate the high turning environment of the low pressure turbine, the tunnel features an adjustable test section capable of inlet and exit angles of 0 to 65 degrees, independent of each other. For the present tests the tunnel is set for the on-design specifications for the highly loaded Pratt \& Whitney PAK-B low-pressure turbine blade with an inlet angle of 35 degrees and an exit angle of 60 degrees. As seen in Fig. 1, this gives the tunnel a total turning of 9.5 degrees. The eight scaled-up blades in the test section have an axial chord of $17.78 \mathrm{~cm}$ ( 7 inches) with an axial chord-to-spacing ratio (solidity) of 1.129 . The blade spacing is $15.75 \mathrm{~cm}$ (6.2 inches) from blade-toblade. Each test blade is molded from solid UItralloy 108 white resin and is seven times engine scale in the axial direction. To further enhance the approximately two-dimensional flowfield of the midspan of the actual blades, each test blade is stretched along the z-axis to $78.63 \mathrm{~cm}$ (30.96 inches) high for an aspect ratio of 4.92 to 1 . The inner and outer walls are shaped to approximate the suction and pressure sides of a blade, respectively. There are 8 blades with nine passages numbered 1 through 8 starting from the inside bend. Boundary layer measurements were taken over the surface of blade 5 .

Measurements of true inlet angle, exit angle, velocity, and turbulence intensity have been made to verify the tunnel operating conditions. The inlet and exit angles were measured with a 30 degrees 3 -hole wedge probe located 1 chord length upstream of the blades with a $5.08 \mathrm{~cm}$ ( 2 inch) inclined manometer. 
All angle measurements were made in the pitch direction ( $\mathrm{x}$-axis) which is perpendicular to the blade inlet plane. The measurements showed a close conformity with on-design specifications. The inlet angle dropped slightly with an increase in turbulence intensity.

Test conditions used in this investigation were for low Reynolds number operation at 43,000, 86,000 and 172,000 based upon inlet velocity and axial chord length. These Reynolds numbers correspond to $102,000,205,000$ and 409,000 using exit velocity and true chord length. The periodicity and uniformity of the inlet velocity and turbulence intensity were measured with a single TSI T1.5 hot wire probe suspended from a 3-axis traverse powered by a Dantec IMC-2 motor controller approximately 1 axial chord length upstream of the blades. Exit velocity and turbulence were measured with the hot wire approximately 1 axial chord length downstream of the blades. The wire was inserted into the test section through slots denoted in Fig. 1 by S-1 and S-4. The 3-axis traverse can travel $60 \mathrm{~cm}$ (23.62 inches) in each axis, providing measurement of the flow properties within $40.64 \mathrm{~cm}$ (16 inches) of the inner wall and $22.86 \mathrm{~cm}$ (9 inches) of the outer wall in slot 1. Pitch traverse movements are measured with a Sony SR50-075A linear scale and a Sony LY-51 digital display. Traverse movements are accurate to within $0.05 \mathrm{~cm}(0.0197$ inches).

The baseline Pratt and Whitney Pak-B blade was tested for freestream turbulence conditions typical of high altitude, low speed flight of reconnaissance UAV's. Turbulence intensities between wakes for engines operating at these conditions are approximately $2-4 \%[4,5]$. Turbulence intensity can be increased from $1 \%$ to $4 \%$ through the use of a square lattice grid immersed into the flow 13.17 chord lengths (234 $\mathrm{cm})$ upstream of test blade 5. The turbulence grid consists of 16 vertical and 10 horizontal stainless steel tubes, each $2.54 \mathrm{~cm}(1 \mathrm{inch})$ in diameter. The tubes are spaced $7.6 \mathrm{~cm}$ ( 3 inches) center to center in accordance with guidelines suggested by Roach [20] for isotropic turbulence.

Hot wire measurements of velocity are accurate to within $0.07 \mathrm{~m} / \mathrm{s}$ for the high speed case to $\pm 0.24 \mathrm{~m} / \mathrm{s}$ for the lowest speed case. Table 1 displays all of the calculated error bands using the method described by Kline and McClintok [21]. The error bands are omitted from the figures for clarity. Turbulence intensity is determined from the standard deviation from the mean of the fluctuating velocity divided by the mean velocity. All hot wire data was recorded using 40,000 samples collected at a sample rate of 10,000 $\mathrm{hz}$. Temperature measurements are made with J-type thermocouples placed at the tunnel inlet, between the turbulence grid and the blade cassette, one on blade 1 , and the test section exit. The thermocouples use a Kaye Instruments Ice Point Thermocouple Reference with the resulting temperatures read into the computer via the HP $3852 \mathrm{~A}$ Data Acquisition/Control Unit. Thermocouples are labeled T-1 through T-4 in Fig. 1.

\begin{tabular}{|l|c|c|}
\hline $\operatorname{Re}$ & $\mathrm{U}(\mathrm{m} / \mathrm{s})$ & $C_{P}$ \\
\hline $0.43 \times 10^{5}$ & \pm 0.24 & \pm 0.59 \\
$0.86 \times 10^{5}$ & \pm 0.15 & \pm 0.18 \\
$1.72 \times 10^{5}$ & \pm 0.70 & \pm 0.04 \\
\hline
\end{tabular}

Table 1: Error bands for hot wire and pressure measurements.

Surface pressures were measured at 40 locations (13 pressure surface, 27 suction surface) around blades 4 and 6 . The surface pressure tap holes are 0.76 $\mathrm{mm}(0.03$ inches) in diameter and are located in the center $22.86 \mathrm{~cm}$ (9 inches) of the blade span. The measurements were made using two 48-channel Scanivalve J-9 scanners each with a 0.5 psid Druck pressure transducer. The scanners are powered by two CTLR 10P/S2-S6 controllers operated via an HP 3852A Data Acquisition/Control Unit and in-house software. The transducers are powered by an HP 6102A DC Power Supply and measurements are read into the operating computer via the HP $3852 \mathrm{~A}$ Data Acquisition/Control Unit and in-house software. The errors in the $C_{p}$ curves was calculated using the method described by Kline and McClintok [21] and are listed in Table 1.

\section{NUMERICAL ANALYSIS}

The flow field is divided into two types of zones in the numerical procedure. O-type grids are used to resolve the flowfield near the airfoils. The O-grids are overlaid on $\mathrm{H}$-grids which are used to resolve the remainder of the flow field. The thin-layer or full Navier-Stokes equations are solved on both the $\mathrm{O}$ and $\mathrm{H}$-grids. The governing equations are cast in the strong conservation form. A fully implicit, finitedifference method is used to advance the solution of the governing equations in time. A Newton-Raphson subiteration scheme is used to reduce the linearization and factorization errors at each time step. The convective terms are evaluated using a third-orderaccurate upwind-biased Roe scheme. The viscous terms are evaluated using second-order accurate central differences and the scheme is second-order accu- 
rate in time. Details of the solution procedure and boundary conditions are discussed in Ref. [22]

Two models were used to simulate the effects of turbulence. The first model is a two-layer algebraic turbulence model based on the work of Baldwin and Lomax (BL) [23]. Several modifications were made to the original BL model based on previous experiences with compressor and turbine geometries [19]. The second model is a two-equation $k-\epsilon$ turbulence model based upon the work of Towne et al. [24]. In the current implementation, the equations for the turbulence kinetic energy and dissipation rate are decoupled from the flow equations and solved using an alternating-direction implicit integration scheme. Since Newton-Raphson subiterations are used at each global time step of the flow solver, decoupling the $k-\epsilon$ equations from the flow solver should not affect the time accuracy of the analysis. The convective fluxes in the turbulence equations were discretized using first-order accurate upwind differences, while the dissipation terms were discretized using secondorder accurate central differences. The $k-\epsilon$ subroutines were constructed in a modular manner to allow the use of different low Reynolds number approximations; the Chien low Reynolds number model has been used in the current investigation [25]. Previous studies have shown that the results predicted using the $k-\epsilon$ model are sensitive to the specified value of the free stream dissipation length scale [19]. The dissipation length scale was not determined in the experimental portion of this study, so a value was chosen based on experience.

The low Reynolds number environment in lowpressure turbines suggests that the flow may be transitional. In the current investigation, natural transition is modeled using the Abu-Ghannam and Shaw model [26]. In the region between the start and end of transition the intermittency function is determined using the model developed by Dhawan and Narasimha [27]. For cases involving separation bubbles the model developed by Roberts [28], and modified by Davis et al. [29], is used.

In the numerical simulations, the O-grid contained $351 \times 41$ (streamwise $\times$ tangential) grid points and the $\mathrm{H}$-grid contained $150 \times 51$ grid points, for a total of 22,041 points (see Fig. 2). The average value of $y^{+}$, the non-dimensional distance of the first grid point above the surface, was approximately 0.1 . The dimensions of the O-grid were arrived at based on the value of $y^{+}$and the number of points within the boundary layer (approximately 20-25), while the dimensions of the $\mathrm{H}$-grid was determined by performing wake convection simulations in the absence of airfoils.

\section{RESULTS}

Three different Reynolds were investigated in this study, $R e=43,000,86,000$ and 172,000 . The turbulence intensity was set at $T u=1 \%$ for all three Reynolds numbers. The flow conditions associated with the three Reynolds numbers are shown in Table 2. The exit Mach numbers, the exit flow angles and the pressure ratios shown in Table 2 were obtained from simulations using the BL and transition models. The inlet Mach numbers, inlet flow angles and Reynolds numbers were similar in the experiments and simulations. Note, because of the low

\begin{tabular}{|l|c|c|c|}
\hline Re & $0.43 \times 10^{5}$ & $0.86 \times 10^{5}$ & $1.72 \times 10^{5}$ \\
\hline$M_{1}$ & 0.011 & 0.023 & 0.046 \\
$M_{2}$ & 0.016 & 0.035 & 0.065 \\
$\alpha_{1}(\mathrm{deg})$ & 35.00 & 35.00 & 35.00 \\
$\alpha_{2}(\mathrm{deg})$ & -57.92 & -59.03 & -59.26 \\
$P_{2} / P_{t 1}$ & 0.9998 & 0.9991 & 0.9970 \\
\hline
\end{tabular}

Table 2: Flow conditions.

Mach numbers all the simulations were performed using double-precision arithmetic.

Figures 3 to 5 illustrate time-averaged Mach contours at the three Reynolds numbers. Figure 3 displays a large, unsteady separated flow region on the suction surface of the airfoil. The amount of flow separation, and the associated unsteadiness, decreases as the Reynolds number is increased. There is a long, shallow separation bubble in the cove region of the pressure surface at all three Reynolds numbers. At the lower two Reynolds numbers the form of transition was bubble transition, while at the highest Reynolds number the transition process varied between natural and bubble transition.

Figures 6 to 8 show time-averaged non-dimensional entropy contours for the three Reynolds numbers. Similar to the Mach contours, the entropy contours show decreasing boundary layer and wake thickness as the Reynolds number is increased. As the amount of separation decreases, the exit flow angle approaches the design value of $\alpha_{2}=60$ degrees (see Table 2). The wake thickness is especially important because it will have a strong influence on the performance of downstream blade rows in an engine environment.

\section{Airfoil Loadings}

Figure 9 illustrates a comparison of the experimental and predicted blade loadings at $R e=43,000$. Included in Fig. 9 are results from fully turbulent 
and transitional simulations with the BL turbulence model, a simulation using the BL model with the boundary layer tripped at $35 \%$ of the axial chord, and a transitional simulation using the $k-\epsilon$ model. The predicted results from the transitional simulation with the BL turbulence model exhibit fair agreement with the experimental data, although the pressure coefficient is underestimated in the separated flow region on the suction surface of the airfoil (implying lower velocities and more pressure recovery in the simulation). In the experiment the flow separated at $60 \%$ of the chord and did not reattach, while in the BL simulation the flow separated at $63 \%$ of the chord and did not reattach (see Table 3 ). The loading from the transitional simulation with the $k-\epsilon$ model shows the same character as the BL solution, but contains a larger undershoot in the separated flow region. Note, however, no attempt was made to tune the dissipation length scale in the $k-\varepsilon$ simulations. The fully turbulent simulation and the simulation with the tripped boundary layer display similar loadings. The increased mixing from the turbulent flow suppresses flow separation and aids in the pressure recovery downstream of the throat.

A comparison of the experimental and predicted blade loadings at $R e=86,000$ is shown in Fig. 10 . Included in Fig. 10 are results from fully turbulent and transitional simulations with the BL turbulence model, a simulation using the $\mathrm{BL}$ model with the boundary layer tripped at $35 \%$ of the axial chord, and a transitional simulation using the $k-\epsilon$ model. The results of the transitional simulation with the BL model show good agreement with the experimental data, exhibiting both the separated flow region (beginning at approximately $72 \%$ axial chord in the experiment and $70 \%$ axial chord in the simulation) and the pressure recovery from approximately $87 \%$ of the chord to the trailing edge. In the experiment the flow reattached at $87 \%$ of the axial chord, while in the simulation the flow did not fully reattach until $95 \%$ of the chord (see Table 3 ). The loading from the simulation with the $k-\epsilon$ model is nearly identical to that in the BL simulation up to $75 \%$ of the axial chord. Whereas the experimental data and BL results indicate a pressure plateau from approximately $75 \%$ chord to $87.5 \%$ chord, the $k-\epsilon$ results show pressure recovery from $75 \%$ of the chord to the trailing edge. The fully turbulent and tripped boundary layer simulations again produced similar loadings.

Figure 11 illustrates a comparison of the experimental and predicted blade loadings at $R e=$ 172,000. Included in Fig. 11 are results from fully turbulent and transitional simulations with the $\mathrm{BL}$ model. The results of the transitional simulation agree closely with the experimental data. In the experiment the flow separated at $75 \%$ of the axial chord and reattached at $83 \%$ of the axial chord. In the simulation, the flow separated at $72 \%$ of the axial chord and reattached at $83 \%$ of the axial chord (see Table 3 ).

\begin{tabular}{|l|c|c|c|}
\hline Re & $0.43 \times 10^{5}$ & $0.86 \times 10^{5}$ & $1.72 \times 10^{5}$ \\
\hline Separation & & & \\
$\left(\mathrm{X} / b_{x}\right)_{\text {expt }}$ & 0.60 & 0.72 & 0.75 \\
$\left(\mathrm{X} / b_{x}\right)_{\text {pred }}$ & 0.63 & 0.70 & 0.72 \\
& & & \\
Reattach & & & \\
$\left(\mathrm{X} / b_{x}\right)_{\text {expt }}$ & - & 0.87 & 0.83 \\
$\left(\mathrm{X} / b_{x}\right)_{\text {pred }}$ & - & 0.95 & 0.83 \\
\hline
\end{tabular}

Table 3: Separation and reattachment data.

\section{Boundary Layer Profiles}

Velocity profiles were obtained normal to the surface at $67.2 \%, 73.0 \%, 79.3 \%, 84.8 \%$ and $89.8 \%$ of the axial chord. While the predicted results show both positive and negative velocities in separated flow regions, the experimental profiles do not show negative velocities because of the operation of the hot wire.

The experimental and predicted velocity profiles at $R e=43,000$ are shown in Fig. 12. The BI and $k-\epsilon$ results shown in Fig. 12 include the effects of transition. The $\mathrm{BL}$ results show good agreement with the experimental data at the $67.2 \%$ and $73.0 \%$ locations, but the experimental data indicate more rapid growth of the separated layer downstream of $73.0 \%$ axial chord. The $k-\epsilon$ results initially show more rapid growth of the separated flow region, but show good agreement with the experimental data from $79.3 \%$ of the chord to the trailing edge.

Figure 13 illustrates the experimental and predicted velocity profiles at $R e=86,000$. The BL and $k-\epsilon$ results show fair agreement with the experimental data at $67.2 \%$ of the chord, display more rapid growth of the boundary layer at $73.0 \%$ and $79.3 \%$ of the chord, then again show fair agreement with the experimental data at $84.8 \%$ and $89.8 \%$ of the chord.

Velocity profiles were not obtained in the experiments at $R e=172,000$ because of limitations of the probe.

\section{Integral Boundary Layer Quantities}

Figure 14 contains the predicted time-averaged skin friction distributions. As the Reynolds num- 
ber was increased from 43,000 to 172,000 the suctionsurface separation point (denoted by $C_{f}<0$ ) moved from approximately $63 \%$ of the axial chord to $72 \%$ of the axial chord. The flow did not reattach at $R e=43,000$, reattaches near the $95 \%$ axial chord at $R e=86,000$ and reat taches at approximately $83 \%$ axial chord at $R e=172,000$. There is a shallow separation region in the cove portion of the pressure surface surface at all three Reynolds numbers.

Figure 15 contains the predicted time-averaged displacement thickness distributions. The displacement thicknesses on the pressure surface of the airfoil are similar for all three Reynolds numbers. The growth of the displacement thickness aft of peak suction on the suction surface increases rapidly as the Reynolds number is decreased (and is caused by increased flow separation).

\section{Cascade Losses}

The experimental and predicted (BL turbulcnce model with transition) cascade losses are shown in Fig. 16. Included in Fig. 16 are the baseline losses, and the losses with a tripped boundary layer. In the experiments, the boundary layer was tripped at $35 \%$ of the axial chord using a trip wire attached to the suction surface of the blade. The location of the trip was determined based on requirement that the flow remain attached in the region where it was separated on the baseline blade. In the simulations the boundary layer was forced to start the transition porcess at $35 \%$ of the chord, and the length of transition was set equal to $10 \%$ of the axial chord. In the baseline experiments the losses initially drop off rapidly as the Reynolds number is increased aboved $R e=43,000$. The experimental losses remain nearly constant between $R e=86,000$ and $R e=172,000$. The predicted losses for the baseline airfoil were greater than the experimental values at all three Reynolds numbers. The predicted results also indicate a more gradual decrease in the loss as the Reynolds number is increased, which is consistent with the longer separation bubbles in the simulations (see Table 3 ).

The losses in the experiments with the tripped boundary layer are nearly constant across the range of Reynolds numbers. The losses are significantly lower than the corresponding baseline losses at $R e=$ 43,000 , but greater then the baseline losses at the two higher Reynolds numbers. The predicted results for the tripped boundary layer show lower losses than the baseline sinulations for the two lower Reynolds number, and similar losses at the higher Reynolds number. These results are consistent with the fact that as the Reynolds number is increased the flow approaches fully turbulent conditions, and tripping the boundary layer should have little effect on the losses. The increased losses at the higher Reynolds numbers in the experiments may be due to the presence of the trip wire.

\section{CONCLUSIONS}

A series of experiments and numerical simulations have been performed for the PAK-B low-pressure turbine geometry. The trends of the predicted results are consistent with the experimental data, and quantitatively the predicted results exhibit fair agreement with the experimental data.

The predicted results and experimental data indicate:

- increased losses and flow separation as the Reynolds number is decreased

- bubble transition at lower Reynolds numbers, and a mixture of bubble and natural transition as the Reynolds number is increased to $R e=172,000$

- boundary layer trips are an effective mechanism for reducing losses at low Reynolds numbers, but not at higher Reynolds numbers

- in the absence of experimentally determined values of the dissipation length scale, the BaldwinLomax turbulence model (in conjunction with a transition model) produces satisfactory results for low Reynolds number flows

\section{ACKNOWLEDGEMENTS}

The first author was supported under NASA Grant NCC3-645.

\section{References}

[1] Simon, F. F. and Ashpis, D. E., "Progress in Modeling of Laminar to Turbulent Transition on Turbine Vanes and Blades," International Conference on Turbulent Heat Transfer, 1996, also NASA TM 107180.

[2] Hodson, H. P., "Boundary Layer Transition and Separation Near the Leading Edge of a HighSpeed Turbine Blade," Journal of Engineering for Gas Turbines and Power, Vol. 107, 1985, pp. $127-134$.

[3] Hodson, H. P., Huntsman, I. and Steele, A. B., "An Investigation of Boundary Layer Development in a Multistage LP Turbine," Journal of Turbomachinery, Vol. 116, 1994, pp. 375-383. 
[4] Halstead, D. E., Wisler, D. C., Okiishi, T. H., Walker, G. J., Hodson, H. P. and Shin, H.-W., "Boundary Layer Development in Axial Compressors and Turbines - Part 1 of 4: Composite Picture," ASME Paper 95-GT-461, Houston, TX, 1995, also published in the ASME Journal of Turbomachinery.

[5] Halstead, D. E., Wisler, D. C., Okiishi, T. H., Walker, G. J., Hodson, H. P. and Shin, H.-W., "Boundary Layer Development in Axial Compressors and Turbines - Part 3 of 4: LP Turbines," ASME Paper 95-GT-463, Houston, TX, 1995, also published in the ASME Journal of Turbomachinery.

[6] Qiu, S. and Simon, T. W., "An Experimental Investigation of Transition as Applied to Low Pressure Turbine Suction Surface Flows," ASME Paper 97-GT-455, Orlando, Fl.

[7] Sohn, K. H., Shyne, R. J. and Dewitt, K. J., "Experimental Investigation of Boundary Layer Behavior in a Simulated Low Pressure Turbine," ASME Paper 98-GT-34, International Gas Turbine and Aeroengine Congress and Exhibition, Stockholm, Sweden, June 2-5, 1998.

[8] Boyle, R. J., Lucci, B. L., Verhoff, V. G., Camperchioli, W. P. and La, H., "Aerodynamics of a Transitioning Turbine Stator Over a Range of Reynolds Numbers," 98-GT-285, International Gas Turbine and Aeroengine Congress and Exhibition, Stockholm, Sweden, June 2-5, 1998.

[9] Lake, J. P., King, P. I., and Rivir, R. B., "Reduction of Separation Losses on a Turbine Blade With Low Reynolds Number," AIAA 99-0242, 37 th AIAA Aerospace Sciences Meeting and Exhibit, Reno, NV, January 11-14, 1999.

[10] Lake, J. P., King, P. I., and Rivir, R. B., "Reduction of Separation Losses on a Turbine Blade with Dimples and V-Grooves at Low Reynolds Numbers," AIAA 00-0738, 38th AIAA Aerospace Sciences Meeting and Exhibit, Reno, January $10-13,2000$.

[11] Mayle, R. E., "The Role of Laminar-Turbulent Transition in Gas Turbine Engines," ASME Paper 91-GT-261, Orlando, FL, 1991.

[12] Reshotko, E., "Boundary Layer Instability, Transition and Control," AIAA Paper 94-0001, Reno, NV, 1994.
[13] Gostelow, J. P., Blunder, A. R. and Walker, G. J., "Effects of Free-Stream Turbulence and Adverse Pressure Gradients on Boundary Layer Transition." ASME Journal of Turbomachinery, Vol. 116, 1994, pp. 392-404.

[14] Gostelow, J. P., Melwani, N. and Walker, G. J., "Effects of Streamwise Pressure Gradient on Turbulent Spot Development, ASME Paper 95GT-303, Houston, TX, 1995.

[15] Boyle, R. J. and Simon, F. F., "Mach Number Effects on Turbine Blade Transition Length Prediction," ASME Paper 98-GT-367, International Gas Turbine and Aeroengine Congress and Exhibition, Stockholm, Sweden, June 2-5, 1998, also accepted for publication in the ASME Journal of Turbomachinery.

[16] Chernobrovkin, A. and Lakshminarayana, B., "Development and Validation of Navier-Stokes Procedure for Turbomachinery Unsteady Flow," AIAA Paper 97-3281, Seattle, WA, 1997, also NASA CR-209303 (1999).

[17] Kang, D. J. and Lakshminarayana, B., "Numerical Prediction of Unsteady Transitional Flow Due to Rotor Stator Interaction," AIAA Paper 97-2752, Seattle, WA, 1997.

[18] Huang, P. G. and Xiong, G., "Transition and Turbulence Modeling of Low Pressure Turbine Flows," AIAA Paper 98-0339, Reno, NV, 1998.

[19] Dorney, D. J., and Ashpis, D., "Study of Low Reynolds Number Effects on the Losses in LowPressure Turbine Blade Rows," International Journal of Turbo and Jet Engines, Vol 16., No. 2, 1999, pp. 91-106

[20] Roach, P. E., "The Generation of Nearly Isotropic Turbulence by Means of Grids," Heat and Fluid Flow, June, Vol. 8, No. 2, pp. 82-92.

[21] Kline, S. J., and McClintok, F. A., "Describing Uncertainties in Single-Sample Experiments," Mechanical Engineering, Vol. 75, No. 1, January, 1953, pp. 3-8.

[22] Dorney, D. J., and Verdon, J. M., "Numerical Simulations of Unsteady Cascade Flow," ASME Journal of Turbomachinery, Vol. 116, No. 4, October, 1994, pp. 665-675.

[23] Baldwin, B. S., and Lomax, H., "Thin Layer Approximation and Algebraic Model for Separated Turbulent Flow", AIAA Paper 78-257, Huntsville, AL, January, 1978. 
[24] Towne, C. E., Schwab, J. R., and Bui, T. T., "Proteus Two-Dimensional Navier-Stokes Computer Code - Version 2.0; Volume 1 - Analysis Description," NASA TM 106336, October, 1993.

[25] Chien, K.-Y., "Predictions of Channel and Boundary-Layer Flows with a Low-ReynoldsNumber Turbulence Model," AIAA Journal, Vol. 20, January, 1982, pp. 33-38.

[26] Abu-Ghannam, B. J., and Shaw, R., "Natural Transition of Boundary Layers - The Effects of Turbulence, Pressure Gradient, and Flow History," IMechE Journal of Mechanical Engineering Science, Vol. 22, No. 5, 1980, pp. 213-228.
[27] Dhawan. S.. and Narasimha. R.. "Some Properties of Boundary Layer Flow During Transition from Laminar to Turbulent Motion." Journal of Fluid Mechanics. Vol 3., 1958.

[28] Roberts. II. B. "Calculation of Laminar Separation Bubbles and Their Effect on Airfoil Performance." AItA Paper 79-028.5. New Orleans. LA. January. 1979.

[20] Daris. R. L.. Carter. J. E., and Reshotko. E.. "Analysis of Transitional Separation Bubbles on Infinite Srept Wings." Alf Journal. Vol. 25. To. 3. March. 1987. pp. $421-428$. 


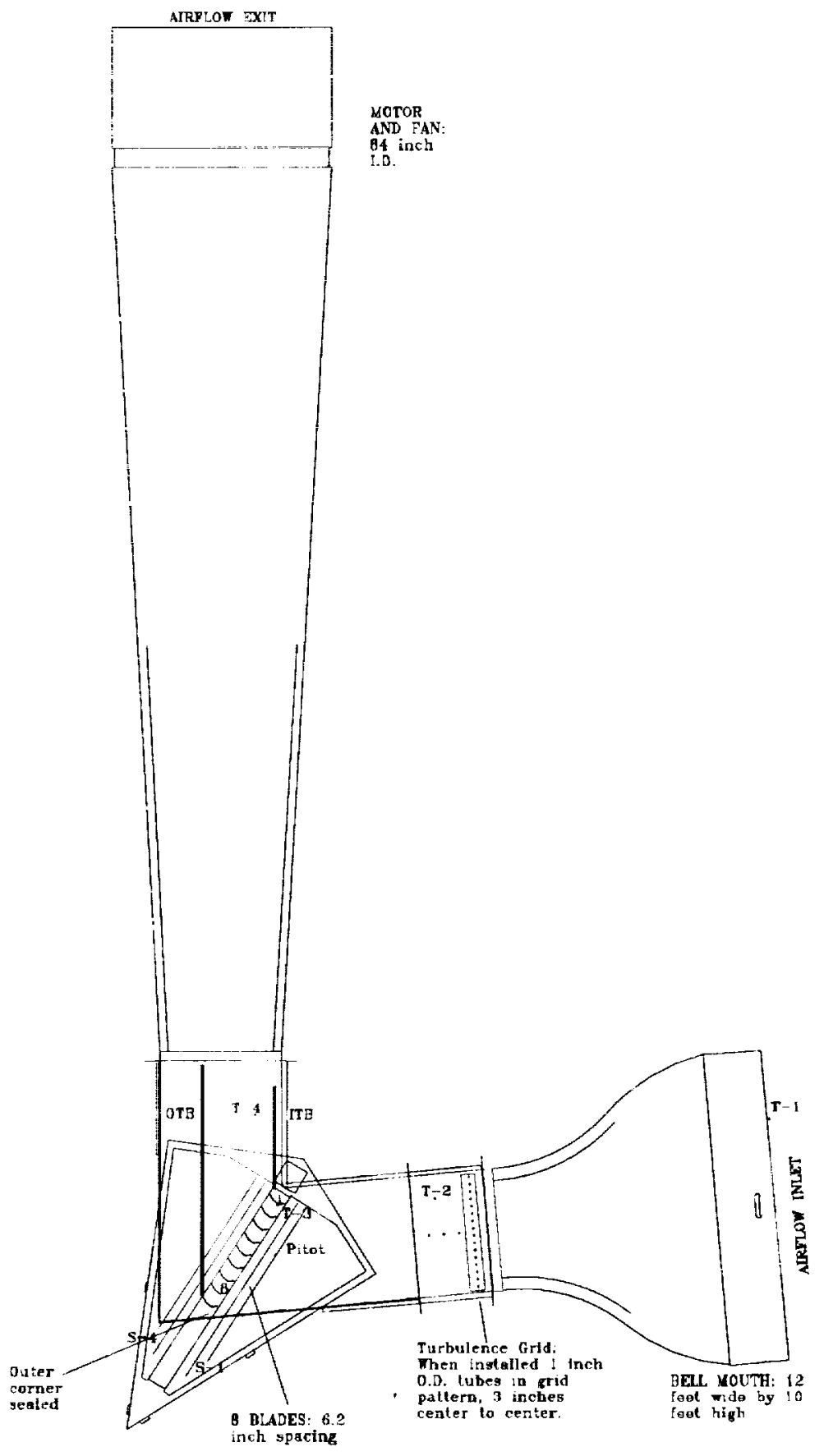




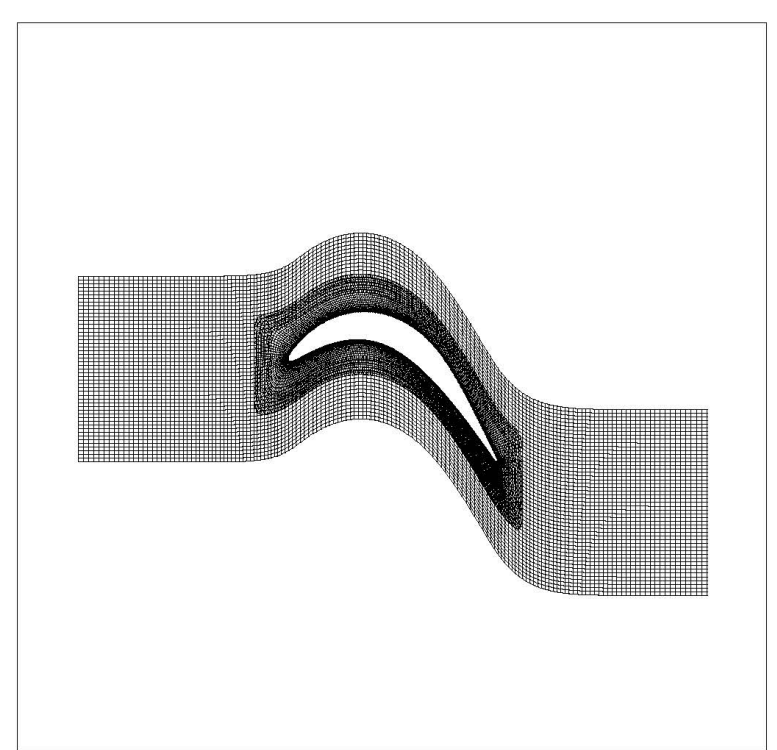

Figure 2: Computational grid for the PAK-B turbine.

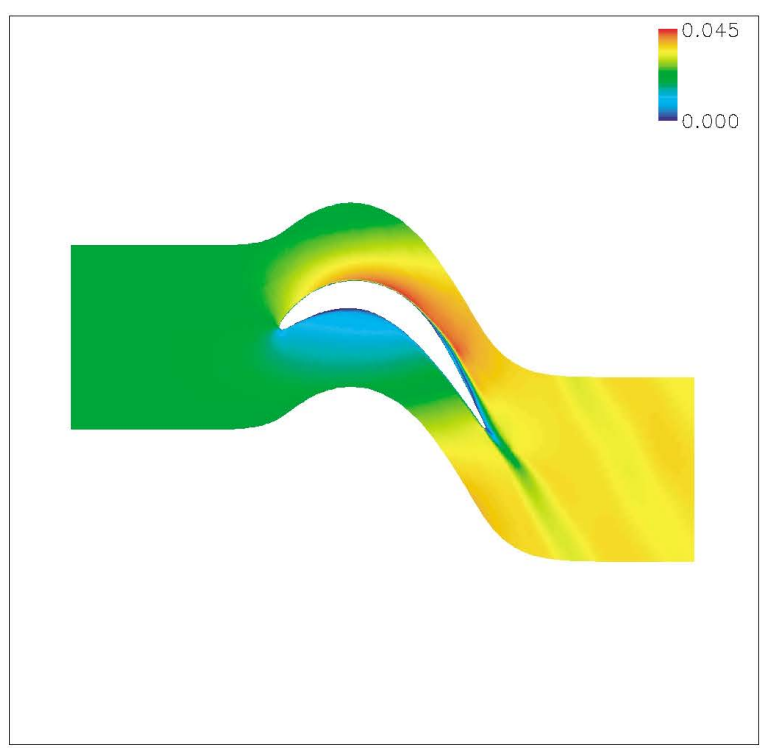

Figure 4: Time-averaged Mach contours - Re = $0.86 \times 10^{5}$.

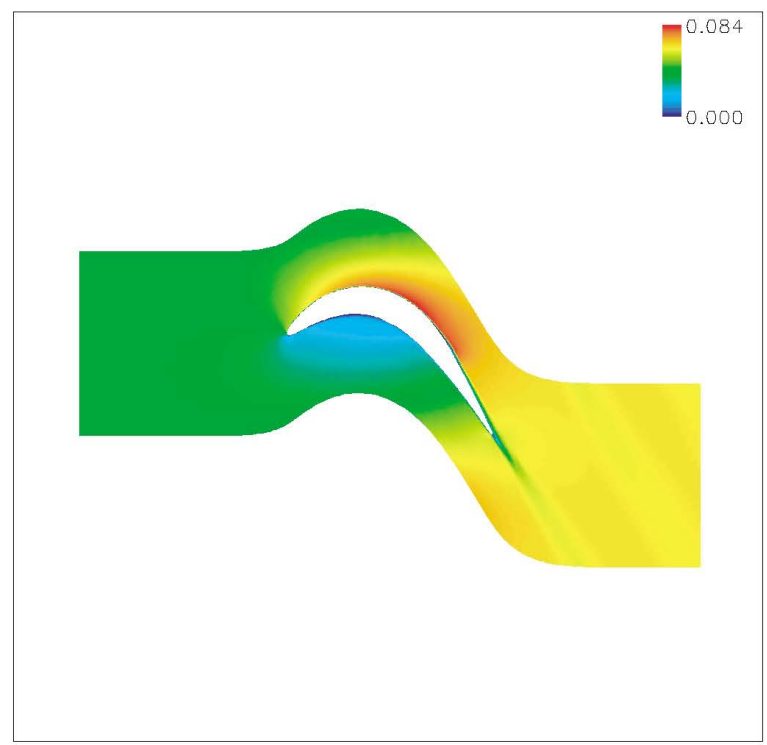

Figure 3: Time-averaged Mach contours - Re $=$ Figure 5: Time-averaged Mach contours - Re = $0.43 \times 10^{5}$. $1.72 \times 10^{5}$. 


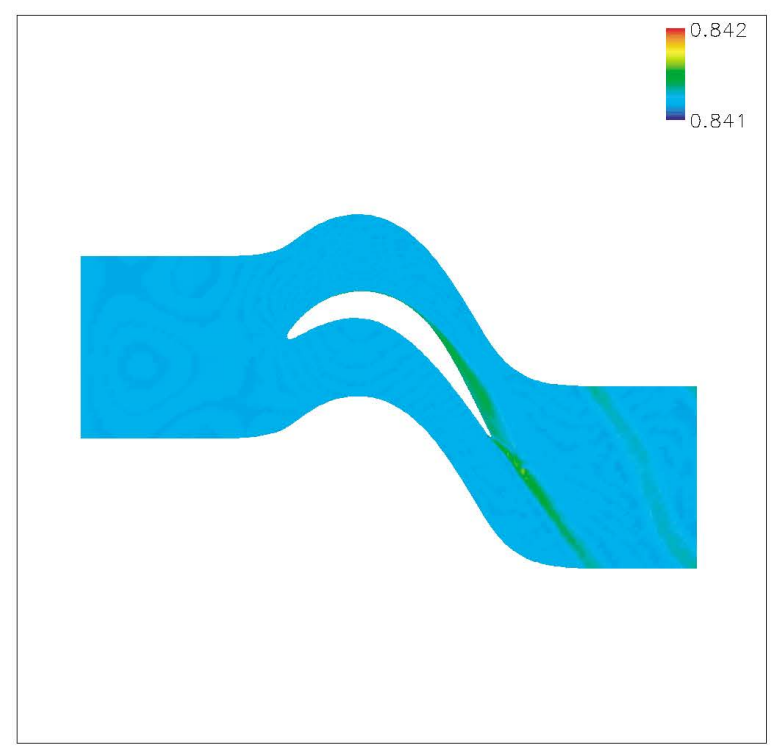

Figure 6: Time-averaged entropy contours - $R e=$ $0.43 \times 10^{5}$.

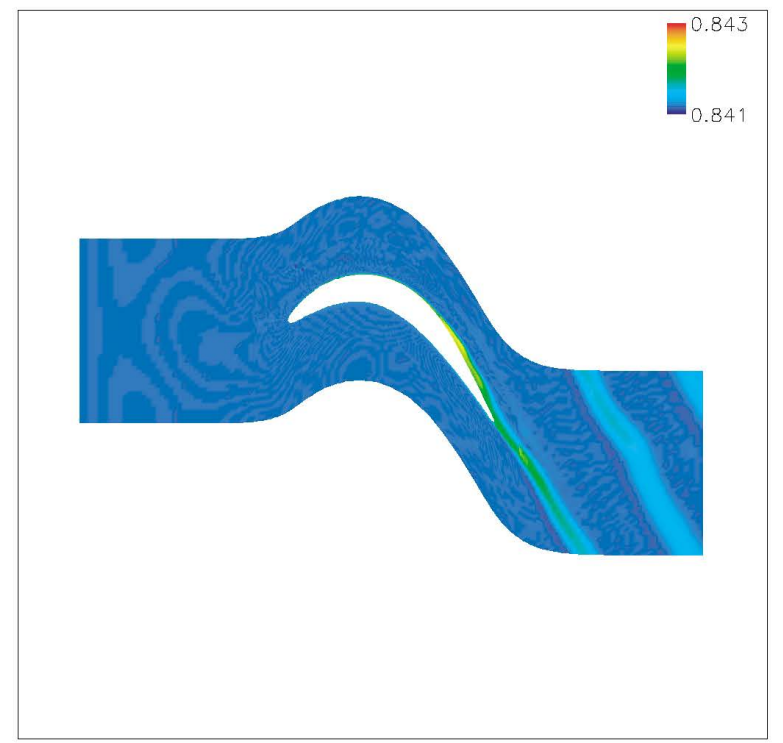

Figure 7: Time-averaged entropy contours - Re = $0.86 \times 10^{5}$.

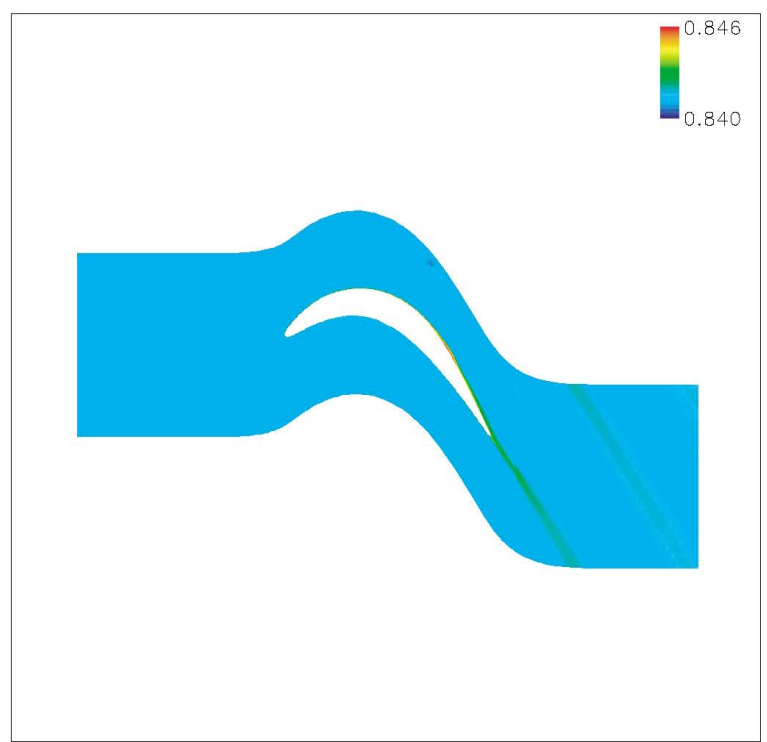

Figure 8: Time-averaged entropy contours - $R e=$ $1.72 \times 10^{5}$.

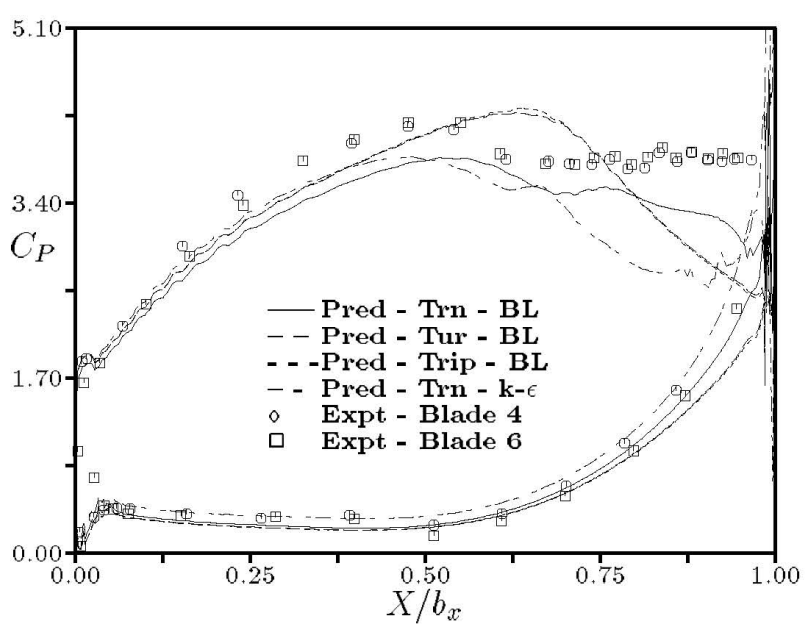

Figure 9: Time-averaged pressure coefficient distribution, $R e=0.43 \times 10^{5}, \mathrm{Tu}=1 \%$. 


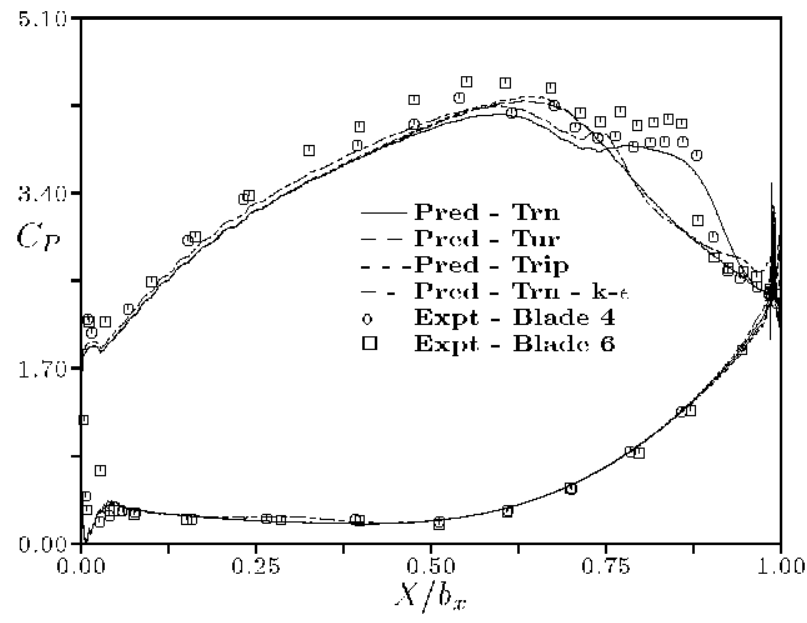

Figure 10: Timc-averaged pressure cocfficient distribution, $R e=0.86 \times 10^{5}, t u=1 \%$.

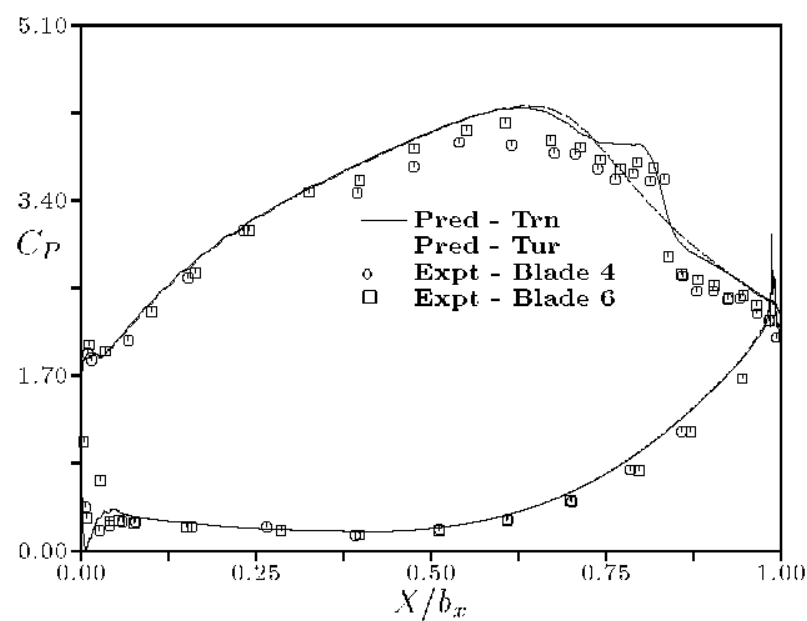

Figure 11: Timc-averaged pressure cocfficient distribution, $R e=1.72 \times 10^{5}, \% u=1 \%$.

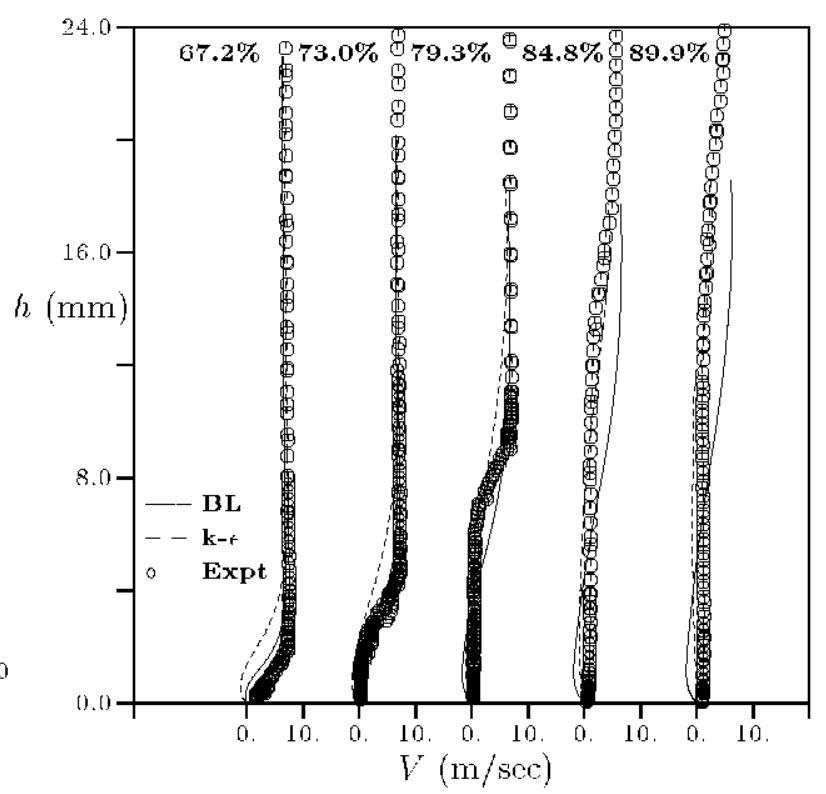

Figure 12: Time-averaged vclocity profiles, $R e=$ $0.43 \times 10^{5}, T^{\prime} u=1 \%$.

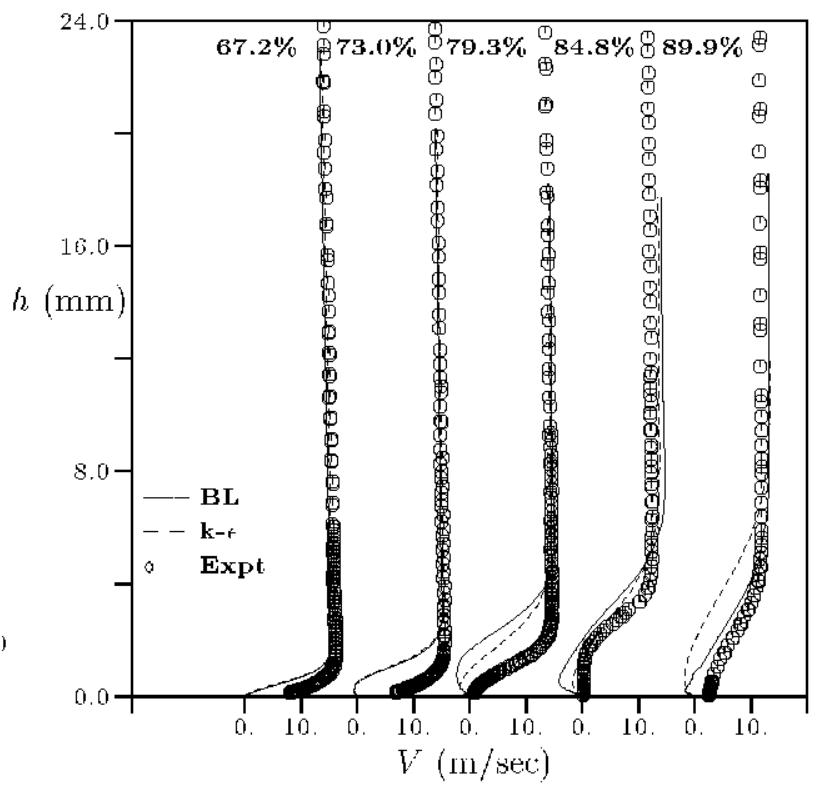

Figure 13: 'l'ime-averaged velocity profiles, Re $=$ $0.86 \times 10^{5}, T u=1 \%$. 


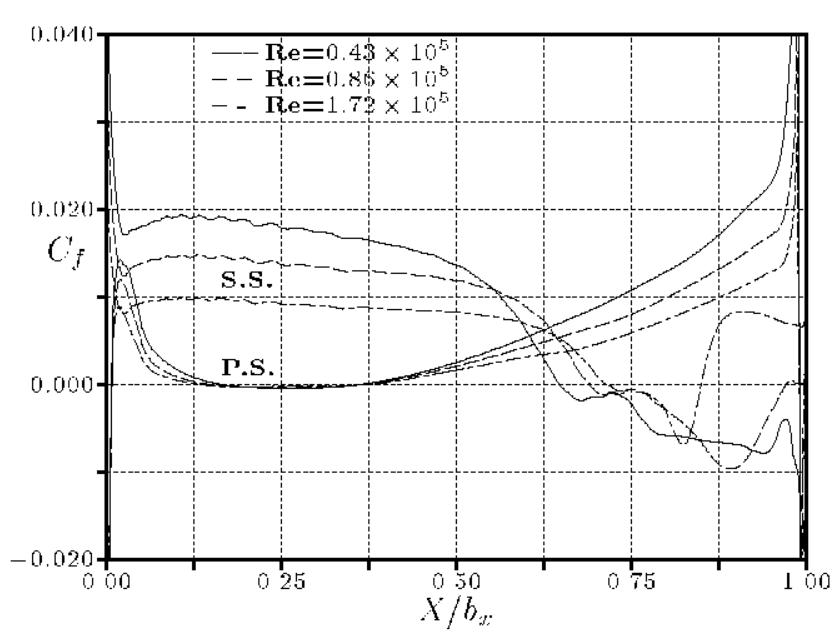

Figure 14: Time-averaged skin friction coeflicient, $R e=0.43,0.86,1.72 \times 10^{5}: T u=1 \%$.

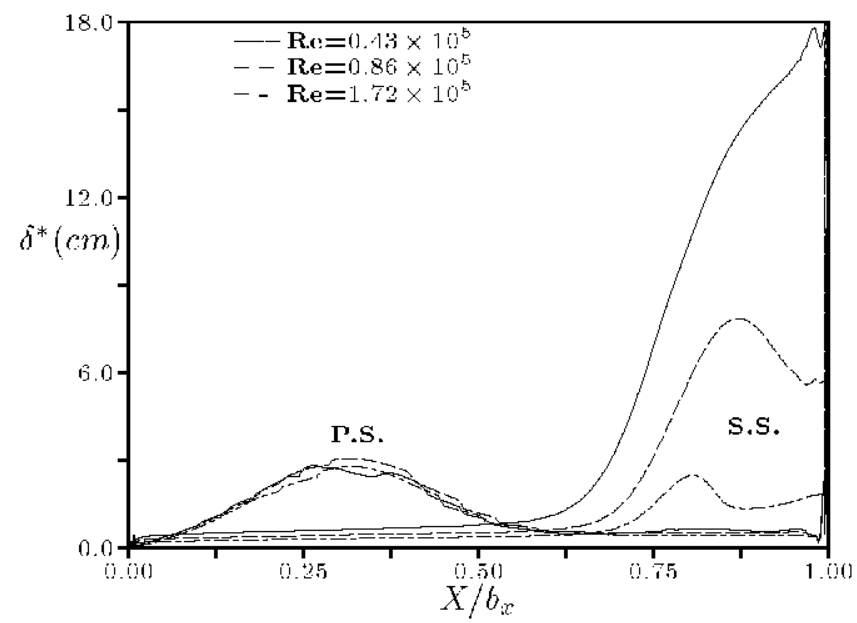

Figure 15: Time-averaged displacement thickness, he $=0.43,0.86,1.72 \times 10^{5}: T u=1 \%$.

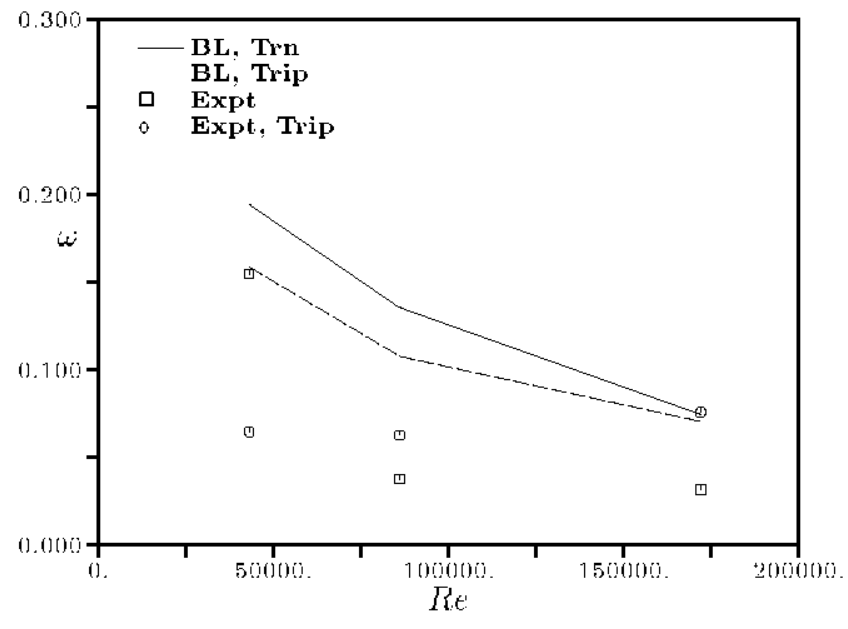

Figure 16: Time-averaged cascade loss, $T u=1 \%$. 


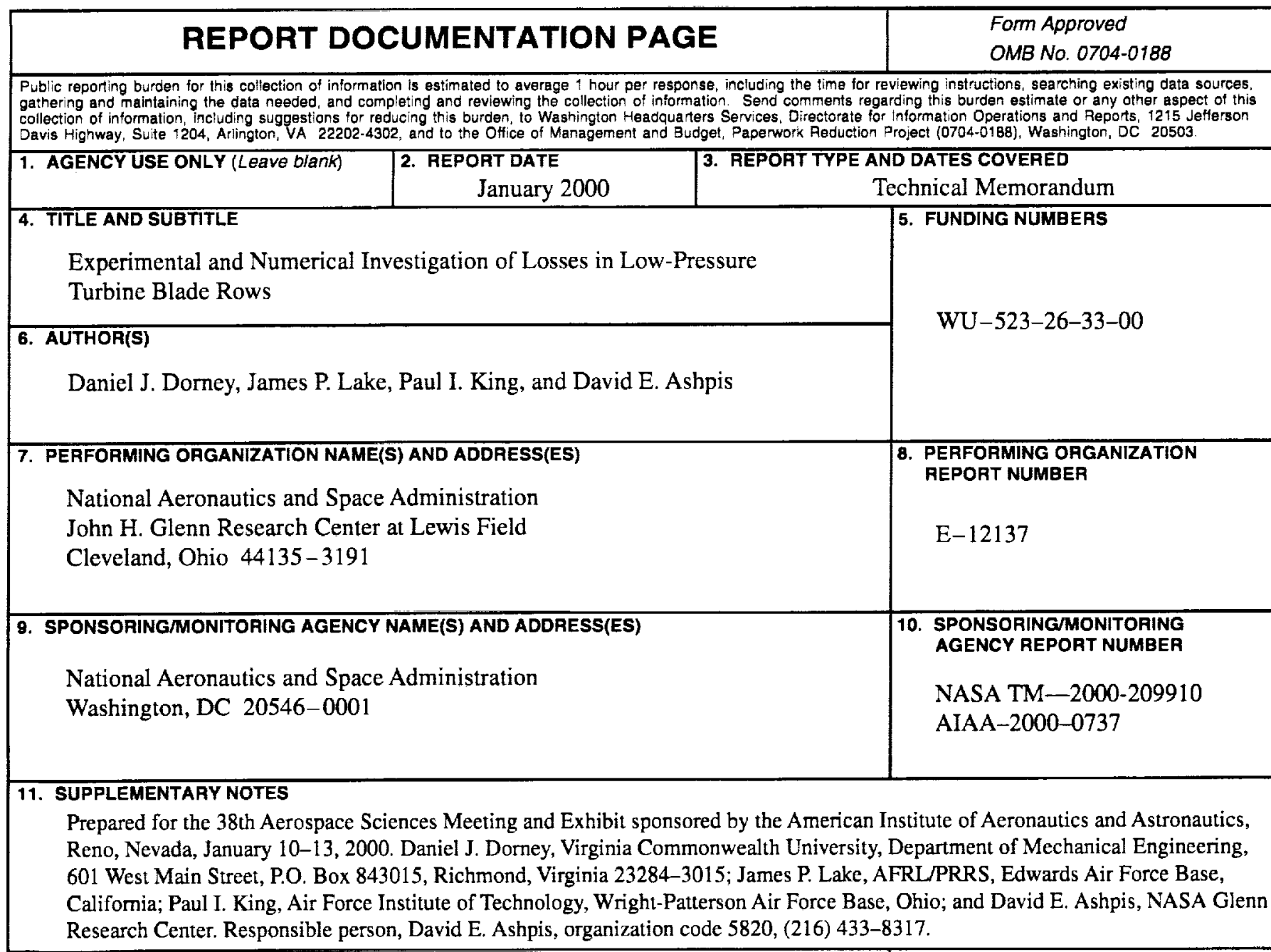

\section{2.. DISTRIBUTION/AVAILABILITY STATEMENT}

Unclassified - Unlimited

Subject Categories: 02, 07, and 34

Distribution: Nonstandard

This publication is available from the NASA Center for AeroSpace Information, (301) 621-0390.

13. ABSTRACT (Maximum 200 words)

Experimental data and numerical simulations of low-pressure turbines have shown that unsteady blade row interactions and separation can have a significant impact on the turbine efficiency. Measured turbine efficiencies at takeoff can be as much as two points higher than those at cruise conditions. Several recent studies have revealed that the performance of low-pressure turbine blades is a strong function of the Reynolds number. In the current investigation, experiments and simulations have been performed to study the behavior of a low-pressure turbine blade at several Reynolds numbers. Both the predicted and experimental results indicate increased cascade losses as the Reynolds number is reduced to the values associated with aircraft cruise conditions. In addition, both sets of data show that tripping the boundary layer helps reduce the losses at lower Reynolds numbers. Overall, the predicted aerodynamic and performance results exhibit fair agreement with experimental data.

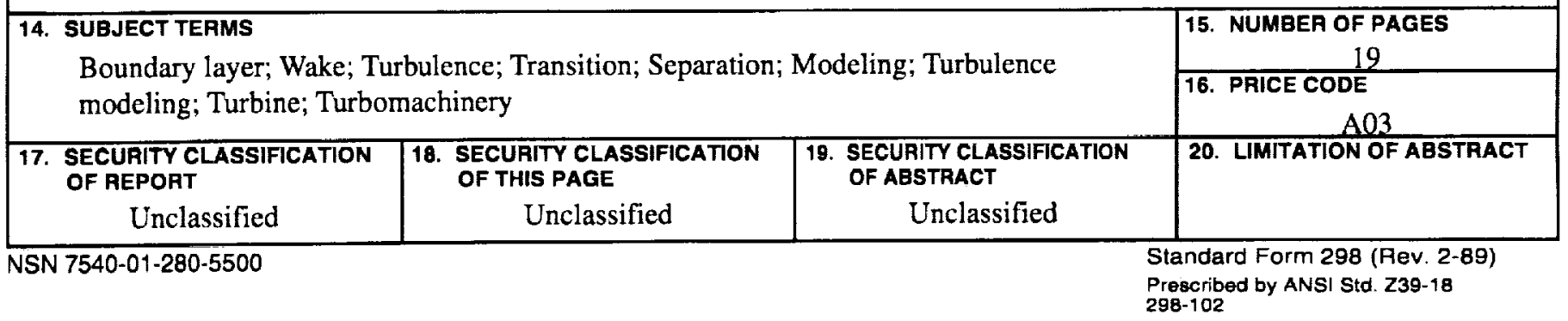

